\title{
PENGARUH KELEMBAGAAN SERTIFIKASI SUMBER BENIH TERHADAP EFISIENSI TATANIAGA BENIH TANAMAN HUTAN : Studi Kasus di Kalimantan Timur dan Kalimantan Selatan
}

\author{
The Influence of the Institution on the Forest Seed Source Certification Towards the \\ Efficiency of Seeds Trading: Case Study in East Kalimantan and South Kalimantan
}

\author{
Faiqotul Falah ${ }^{1)}$ dan/and Bramasto Nugroho ${ }^{2)}$ \\ ${ }^{1)}$ Balai Penelitian Teknologi Perbenihan Samboja \\ Jl. Sukarno-Hatta Km 38 Samboja PO Box 578 Balikpapan 76112 \\ ${ }^{2)}$ Fakultas Kehutanan Institut Pertanian Bogor \\ Kampus IPB Darmaga, Kotak Pos 168 Bogor 16001
}

Naskah masuk : 26 Oktober 2009; Naskah diterima : 10 Mei 2010

\begin{abstract}
The forest and land rehabilitation activities need abundant seed supplies from high quality seed sources. To guarantee the validity of forest seed source class and the products' quality, Ministry of Forestry issued the seed source certification policy. There are some rules of the game (called institution) applied in the relationship among stakeholder of seed sources certification. From the economical view, the institution applied on seed sources activities expected to make efficiency for the seeds business among the traders. This paper presents the efficiency of the institution on the forest seed source certification in South and East Kalimantan. This study was conducted by: 1) identifying the financial components and analyzing financial feasibility of seed source company, and 2) identifying and analyzing the benefit distribution among stakeholders. The financial analysis showed that seed sources business are feasible and the transaction cost of certification is not significant, indicating that the institution of the forest seed sources certification is efficient. But it could be more efficient if the benefit distribution among the seed traders could be shared in balance, by shortening the traders' path and empowering the bargaining position of the seed producers.
\end{abstract}

Keywords: Seed sources certification, seed trading, efficiency, institution, feasibility, transaction cost, benefit distribution

\begin{abstract}
ABSTRAK
Kegiatan rehabilitasi hutan memerlukan pasokan benih dalam jumlah yang berlimpah dari sumber benih berkualitas. Sertifikasi sumber benih diterbitkan untuk menjamin kebenaran kelas sumber benih dan kualitas produknya. Dalam kegiatan sertifikasi sumber benih terdapat aturan main dalam relasi antar pihak atau disebut kelembagaan. Dari sudut pandang ekonomi, kelembagaan yang berlaku dalam kegiatan sertifikasi sumber benih ini diharapkan dapat membuat manfaat yang diperoleh para pihak seimbang dengan pengorbanan sumberdaya yang dikeluarkan (efisien). Tulisan ini memaparkan hasil penelitian mengenai efisiensi kelembagaan sertifikasi sumber benih tanaman hutan di Kalimantan Timur dan Kalimantan Selatan. Kriteria efisiensi yang digunakan adalah manfaat yang diperoleh parapihak seimbang dengan pengorbanan sumberdaya yang dikeluarkan dan biaya transaksi yang dikeluarkan dalam relasi antar pihak dapat diminimumkan. Penelitian ini dilaksanakan dengan cara : 1) Menganalisis kelayakan finansial pengelola sumber benih; 2) Mengidentifikasi dan menghitung biaya transaksi; dan 3) Mengidentifikasi dan menganalisis distribusi manfaat antar pihak yang terlibat dalam tataniaga benih. Hasil analisis finansial memperlihatkan bahwa pengusahaan sumber benih bersertifikat layak secara finansial dan biaya transaksi sertifikasi tidak signifikan (minimum), namun distribusi manfaat antar pelaku tataniaga perbenihan dapat lebih seimbang dengan jalan memperpendek saluran tataniaga dan memperkuat posisi tawar pengelola sumber benih.
\end{abstract}

Kata kunci: Sertifikasi sumber benih, tataniaga benih, efisiensi, kelembagaan, kelayakan finansial, biaya transaksi, distribusi manfaat 


\section{PENDAHULUAN}

Saat ini kegiatan rehabilitasi hutan menjadi prioritas pembangunan kehutanan Indonesia. Upaya merehabilitasi kawasan hutan serta pembangunan hutan tanaman memerlukan pasokan benih berkualitas baik dalam jumlah yang banyak. Salah satu upaya untuk menyediakan benih berkualitas adalah melalui pembangunan sumber benih. Untuk memberikan jaminan kebenaran kelas sumber benih maka dipandang perlu adanya sertifikasi sumber benih tanaman hutan (Permenhut No P.1/2009). Hal ini dimaksudkan sebagai upaya perlindungan konsumen produk sumber benih.

Secara kualitatif, dari sudut pandang konsumen benih, tujuan dilakukannya sertifikasi sumber benih adalah untuk memberikan jaminan mutu sumber benih. Namun dari sudut pandang pengelola sumber benih serta pengada dan pengedar benih dan/atau bibit, ada pula tujuan ekonomis yaitu memperoleh keuntungan finansial. Terpenuhinya motif ekonomi akan memotivasi pengelola sumber benih untuk meningkatkan kualitas produksi benih. Menurut hasil penelitian Falah et al. (2008), terdapat beberapa fenomena masalah terkait dengan aspek ekonomi dalam kegiatan sertifikasi perbenihan tanaman hutan di Kalimantan, yaitu :

1. Belum ada tarif resmi sertifikasi sumber benih bersertifikat. Tarif sertifikasi akan mempengaruhi besarnya biaya produksi benih sehingga menentukan pula besarnya marjin keuntungan bagi pengelola sumber benih bersertifikat.

2. Beberapa pengelola sumber benih menganggap sertifikasi sumber benih belum dapat memberi keuntungan finansial yang signifikan.

3. Adanya ketidakseimbangan distribusi informasi pemasaran antara pihak pengelola sumber benih sebagai produsen dengan konsumen.

Dalam kegiatan sertifikasi sumber benih terdapat aturan main yang melibatkan beberapa pemangku kepentingan, atau disebut kelembagaan. Suatu kelembagaan dianggap efisien apabila manfaat yang diperoleh parapihak seimbang dengan pengorbanan sumberdaya yang dikeluarkan dan biaya transaksi yang dikeluarkan dalam relasi antar pihak dapat diminimumkan.

Adanya fenomena masalah di atas menimbulkan pertanyaan berikut : Apakah kelembagaan sertifikasi sumber benih tanaman hutan di Kalimantan Timur dan Kalimantan
Selatan dapat menjaga efisiensi usaha penyediaan benih? Pertanyaan tersebut kemudian diterjemahkan menjadi tiga pertanyaan khusus sebagai berikut:

1. Berapa besar biaya transaksi sertifikasi sumber benih?

2. Apakah pengusahaan sumber benih bersertifikat cukup layak secara finansial?

3. Bagaimana distribusi manfaat antar pelaku dalam tataniaga benih dari sumber benih bersertifikat?

Tulisan ini bertujuan untuk menjawab pertanyaan di atas, yaitu mengkaji efisiensi sertifikasi sumber benih tanaman hutan di Kalimantan Timur dan Kalimantan Selatan, sehingga dapat menghasilkan rekomendasi bagi penyempurnaan kebijakan yang terkait.

\section{METODOLOGI PENELITIAN}

\section{A. Lokasi dan Waktu Penelitian}

Pengambilan data dilaksanakan pada bulan Mei dan Juni 2009. Pengambilan sampel sumber benih yang menjadi lokasi penelitian dilakukan secara purposive, yaitu dipilih sumbersumber benih yang mewakili masing-masing kategori sumber benih bersertifikat seperti yang disebutkan dalam Falah (2008), yaitu : 1) sumber benih skala kecil yang diusahakan oleh lembaga swadaya masyarakat (LSM) atau kelompok tani (KT); 2) skala menengah, yang diusahakan oleh perusahaan bukan HTI; dan 3) skala besar, yang diusahakan oleh pemegang Ijin Usaha Pemanfaatan Hasil Hutan Kayu Hutan Tanaman (IUPHHK -HT). Untuk masing-masing kategori diambil dua sampel sumber benih, yaitu :

a. Skala kecil, di sumber benih Shorea sp. di Kec. Batang Alai, Kab. Hulu Sungai Selatan yang dikelola Kelompok Tani Meratus Sejahtera (KT MS), dan sumber benih Aquilaria malaccensis di Kab. Balangan, Kalimantan Selatan, yang dikelola LSM Gaharu Persada (LSM GP).

b. Skala menengah, yaitu sumber benih Shorea sp. di Kec. Samboja, Kab. Kutai Kartanegara, Kalimantan Timur yang dikelola PT Graha Kaltim Sentosa (PT GKS) serta sumber benih Aquilaria malaccensis di Samarinda, Kalimantan Timur yang dikelola CV Girilusindo Landscape (CV GL).

c. Skala besar, yaitu sumber benih Shorea sp. dan Swietenia macrophhylla yang dikelola 
PT ITCI Kartika Utama (PT IKU) di Kenangan, Kab. Kutai Kartanegara, Kalimantan Timur, serta sumber benih Acacia mangium yang dikelola PT Inhutani III (PT INH 3) di Kab. Tanah Laut, Kalimantan Selatan.

\section{B. Metode Penelitian}

Pengambilan data primer bersumber dari para pengelola sumber benih serta pengada bibit terdaftar, berupa identifikasi dan pengukuran komponen biaya produksi, biaya pemasaran, harga jual, harga beli, serta komponen dan besaran biaya transaksi sertifikasi sumber benih. Pengambilan data primer dilakukan dengan metode wawancara terstruktur dengan bantuan kuesioner. Sedangkan analisis data yang dilakukan adalah sebagai berikut :

\section{a. Analisis kelayakan finansial pengusahaan sumber benih bersertifikat}

Analisis kelayakan finansial dilakukan untuk menjawab pertanyaan apakah pengelolaan sumber benih bersertifikat layak secara ekonomis. Metode analisis kelayakan finansial dalam penelitian ini menggunakan kriteria $\mathrm{Net}$ Present Value (NPV), Benefit Cost Ratio (BCR) dan Internal Rate of Return (IRR).

\section{b. Analisis Farmer's Share}

Kohl dan Uhl (2002) mendefinisikan Farmer's share (Fs) sebagai persentase harga yang diterima oleh petani sebagai imbalan dari kegiatan usahatani yang dilakukannya dalam menghasilkan suatu komoditas. Nilai Fs ditentukan oleh besarnya rasio harga yang diterima produsen $\left(\mathrm{P}_{\mathrm{f}}\right)$ dan harga yang dibayarkan oleh konsumen $\left(\mathrm{P}_{\mathrm{r}}\right)$, atau dirumuskan dengan persamaan berikut :

$$
F S=\left(\mathrm{P}_{\mathrm{f}} / \mathrm{P}_{\mathrm{r}}\right) \times 100 \%
$$

\section{c. Analisis penyebaran marjin tataniaga}

Marjin tataniaga adalah perbedaan harga yang terjadi antara lembaga satu dengan yang lain dalam saluran tataniaga komoditas yang sama. Secara matematis marjin tataniaga dinyatakan sebagai berikut:

dimana:

$$
\mathrm{M}_{\mathrm{i}}=\mathrm{P}_{\mathrm{si}} \mathrm{P}_{\mathrm{bi}} \text { dan } \mathrm{M}_{\mathrm{i}}=\mathrm{C}_{\mathrm{i}}+\Pi_{\mathrm{i}}
$$

$\mathrm{M}_{\mathrm{i}}=$ marjin tataniaga lembaga tataniaga ke-i;

$\mathrm{P}_{\mathrm{si}}=$ harga penjualan lembaga tataniaga ke-i;
$\mathrm{P}_{\mathrm{b}}=$ harga pembelian lembaga tataniaga ke-I;

$\mathrm{C}_{\mathrm{i}}=$ biaya pemasaran lembaga tataniaga ke- $\mathrm{i}$;

$\Pi_{i}=$ keuntungan pemasaran lembaga tataniaga ke-I, sehingga total marjin tataniaga adalah :

$$
\mathrm{M}={ }^{\mathrm{n}} ?_{\mathrm{i}=1} M_{i}, \quad \mathrm{i}=1,2,3, \ldots \mathrm{n}
$$

Tingkat efisiensi juga dilihat melalui penyebaran marjin tataniaga, yaitu berdasarkan rasio keuntungan $(\mathrm{K})$ terhadap biaya pemasaran (B) pada masing-masing lembaga pemasaran, yang dirumuskan sebagai berikut:

$$
\text { Rasio K-B = p / C }
$$

\section{d. Analisis biaya transaksi sertifikasi sumber benih}

Tujuan dilakukan analisis biaya transaksi dalam penelitian ini adalah untuk melihat besarnya biaya eksternalitas dari sertifikasi sumber benih. Dalam penelitian ini komponen biaya transaksi yang diukur adalah : a). biaya informasi; b) biaya negosiasi, meliputi pengorbanan tenaga dan uang untuk mencapai kesepakatan, termasuk fee dan komisi; dan c) biaya pemantauan dilihat dari realisasi fisik yang dilakukan BPTH dan Dinas Propinsi atau Kabupaten/Kota untuk melakukan kunjungan atau komunikasi, dan biaya untuk pelaporan dari sisi produsen dan pengedar benih atau bibit.

Kelembagaan sertifikasi sumber benih dinilai efisien apabila total marjin pemasaran minimum, distribusi marjin pemasaran merata pada masing-masing lembaga tataniaga, biaya transaksi minimum, serta distribusi informasi merata antar pemangku kepentingan.

\section{HASIL DAN PEMBAHASAN}

\section{Analisis kelayakan finansial dan biaya transaksi sertifikasi sumber benih}

Komponen analisis kelayakan finansial dalam usaha pengelolaan sumber benih (SB) bersertifikat adalah sebagai berikut :

a. Pengeluaran, meliputi biaya investasi, biaya operasional dan biaya pemasaran. Biaya investasi meliputi biaya izin usaha, retribusi, sewa lahan, biaya pembangunan sumber benih, pendirian bangunan dan gedung, pengadaan peralatan, dan biaya sertifikasi. Biaya operasional meliputi biaya produksi benih (mencakup biaya pengunduhan, sortasi, penjemuran, dan penyimpanan 
benih) dan biaya pemeliharaan pohon induk, serta biaya produksi bibit (mencakup biaya penyiapan media dan polibag, pengunduhan dan sortasi benih, biaya pembibitan dan pemeliharaan di persemaian) dan biaya pemeliharaan pohon induk. Biaya pemasaran meliputi biaya transportasi dan biaya transaksi pemasaran. Biaya transaksi pemasaran ini meliputi biaya komunikasi dan biaya negosiasi untuk mewujudkan kontrak. b. Pemasukan, meliputi pendapatan yang diperoleh dari hasil penjualan benih atau bibit.

Pada analisis kelayakan finansial ini diasumsikan pengeluaran dan pemasukan setiap tahun selama 5 (lima) tahun adalah tetap. Nilai interest rate ditentukan sebesar $13.52 \%$, sesuai tingkat suku bunga rata-rata bank umum pada bulan Juni 2009 menurut Bank Indonesia (Bank Indonesia, 2009). Karakteristik pengelola sumber benih disajikan pada Tabel 1 .

Tabel (Table) 1. Karakteristik pengelola sumber benih yang menjadi informan penelitian (The characteristics of seed producers in this research)

\begin{tabular}{|l|l|l|l|l|}
\hline $\begin{array}{c}\text { Nama pengelola } \\
\text { sumber benih } \\
\begin{array}{c}\text { Name of seed } \\
\text { producers })\end{array}\end{array}$ & $\begin{array}{c}\text { Jenis } \\
\text { produk } \\
\text { (type of } \\
\text { product) }\end{array}$ & $\begin{array}{c}\text { Kelas sumber benih } \\
\text { (seed sources } \\
\text { classification) }\end{array}$ & $\begin{array}{c}\text { Asal pohon } \\
\text { induk } \\
\text { the source } \\
\text { of mother } \\
\text { trees })\end{array}$ & $\begin{array}{c}\text { Harga jual } \\
\text { mempertimbangkan } \\
\text { sertifikat atau tidak } \text { the } \\
\text { consideration of the } \\
\text { certificate on the } \\
\text { selling } \text { price) }\end{array}$ \\
\hline PT Inhutani 3 & Benih & $\begin{array}{l}\text { Tegakan Benih } \\
\text { Provenan (TBP) }\end{array}$ & $\begin{array}{l}\text { Hutan } \\
\text { tanaman } \\
\text { (HT) }\end{array}$ & Ya \\
\hline LSM GP & Bibit & $\begin{array}{l}\text { Tegakan Benih } \\
\text { Teridentifikasi (TBT) }\end{array}$ & HA & Ya \\
\hline KT MS & Bibit & TBT & HA & Tidak \\
\hline PT IKU & Bibit & $\begin{array}{l}\text { TBT (meranti), Areal } \\
\text { Produksi Benih (APB, } \\
\text { mahoni) }\end{array}$ & HA, HT & $\begin{array}{l}\text { Ya (TBT meranti), } \\
\text { tidak (APB mahoni) }\end{array}$ \\
\hline PT GKS & Bibit & TBT & HA & Ya \\
\hline CV GL & Bibit & TBT & HA & Tidak \\
\hline
\end{tabular}

Biaya pembangunan sumber benih pada hutan alam meliputi biaya survei, penataan area, dan inventarisasi tegakan. Sedang biaya pembangunan sumber benih pada hutan tanaman meliputi biaya pembelian materi genetik, survei area, persiapan lahan, penanaman, penataan area, dan inventarisasi tegakan. Dalam penelitian ini ada satu pengelola sumber benih yang tidak mengeluarkan biaya pembangunan sumber benih, yaitu KT Meratus Sejahtera yang sumber benihnya berada di wilayah hutan lindung dan biaya pembangunan sumber benihnya berasal dari Dinas Kehutanan Kab. Hulu Sungai Tengah. Hasil analisis finansial menunjukkan bahwa usaha pengelolaan sumber benih layak secara finansial, baik untuk yang berskala kecil, menengah, maupun besar (Tabel 2). 
Tabel (Table) 2. Hasil analisis kelayakan finansial pengusahaan sumber benih bersertifikat (The results of financial analysis on the certificated seed sources bussiness)

\begin{tabular}{|c|c|c|c|c|c|}
\hline $\begin{array}{l}\text { Nama pengelola } \\
\text { sumber benih (Name } \\
\text { of seed source } \\
\text { company) }\end{array}$ & NPV (Rp) & BCR & IRR (\%) & $\begin{array}{c}\text { Biaya } \\
\text { transaksi per } \\
\text { sertifikat } \\
\text { (transaction } \\
\text { cost per } \\
\text { certificate) (Rp) }\end{array}$ & $\begin{array}{c}\text { Rasio biaya } \\
\text { transaksi } \\
\text { dengan NPV } \\
\text { (ratio of } \\
\text { transaction cost } \\
\text { and NPV) }\end{array}$ \\
\hline \multicolumn{6}{|l|}{ Kalimantan Selatan } \\
\hline $\begin{array}{l}\text { PT Inhutani } 3 \text { (produk } \\
\text { : akasia) }\end{array}$ & $112,793,535$ & 1.088 & $78.49 \%$ & $5,000,000$ & 0.089 \\
\hline LSM GP (gaharu) & $202,036,364$ & 1.288 & $110.14 \%$ & $3,500,000$ & 0.017 \\
\hline KT MS (meranti) & $11,543,436$ & 1.075 & $29.32 \%$ & $\begin{array}{r}\text { tanpa biaya } \\
\text { sertifikasi }\end{array}$ & - \\
\hline \multicolumn{6}{|l|}{ Kalimantan Timur } \\
\hline $\begin{array}{l}\text { PT IKU } \\
\text { (difokuskan pada } \\
\text { meranti dan Mahoni) }\end{array}$ & $180,229,622$ & 1.309 & $173.70 \%$ & $1,000,000$ & 0.040 \\
\hline PT GKS (meranti) & $107,640,702$ & 1.144 & $189,82 \%$ & $6,000,000$ & 0.060 \\
\hline CV GL (gaharu) & $62,866,731$ & 1.119 & $37.79 \%$ & $10,000,000$ & 0.160 \\
\hline
\end{tabular}

Sumber : data primer, diolah

Hasil perhitungan selengkapnya dapat dilihat pada Lampiran 1. Besarnya nilai BCR dan IRR dipengaruhi antara lain oleh :

1. Besarnya permintaan akan hasil produksi. LSM GP dan PT IKU lebih besar BCRnya dibanding PT Inhutani 3 karena permintaan akan hasil produksinya yang lebih banyak. Sedang PT Inhutani 3 hanya 32\% produknya yang diserap pasar.

2. Kelas sumber benih yang menentukan harga produk. Makin tinggi kelas sumber benih, makin tinggi harga produknya, baik berupa benih atau bibit. Sebagai contoh, kelas sumber benih PT Inhutani 3 adalah TB Provenans yang harga benihnya 4 (empat) kali harga benih dari sumber benih non sertifikat.

3. Ketegasan pengelola sumber benih menetapkan harga produk bersertifikat lebih tinggi daripada non sertifikat, yaitu di PT Inhutani 3, LSM GP, dan PT GKS.

Nilai biaya transaksi didapatkan dari besarnya biaya tidak resmi yang dikeluarkan pemohon sertifikat untuk keperluan komunikasi, biaya negosiasi yang meliputi akomodasi, konsumsi, transport lokal, dan biaya lain-lain bagi anggota tim penilai sertifikasi. Sementara dari BPTH tidak dikeluarkan biaya untuk kunjungan monitoring karena pembinaan dan monitoring dilakukan sekaligus saat kunjungan untuk sertifikasi bibit. Dalam Tabel 2 nampak bahwa besaran biaya transaksi sertifikasi ternyata tidak signifikan dibanding besarnya keuntungan yang didapatkan, kecuali di CV GL. Meski demikian akan lebih baik apabila biaya tidak resmi ini dapat diminimalkan. Berdasar hasil wawancara dengan informan pengada benih/ bibit, ternyata mereka tidak berkeberatan bila harus menanggung biaya penilaian lapangan serta membayar jasa penerbitan sertifikat, asalkan benar-benar merupakan tarif resmi, dan besarnya pungutan proporsional dengan keuntungan yang didapat pengusaha dengan adanya sertifikat.

\section{Analisis sensitivitas}

Analisis sensitivitas dilakukan untuk menguji kepekaan suatu kegiatan terhadap berbagai faktor yang mungkin terjadi. Setiap asumsi yang diberikan bersifat ceteris paribus. Dalam penelitian ini, asumsi yang digunakan dalam analisis sensitivitas ini adalah apabila terjadi penurunan penjualan sebesar $20 \%$, dan adanya kenaikan harga pokok produksi (HPP) sebesar 10\%, serta apabila terjadi interaksi antara penurunan penjualan dengan kenaikan HPP. Pada analisis sensitivitas ini, kenaikan HPP dikenakan 
pada biaya operasional dan biaya pemasaran per tahun selama 5 tahun (Tabel 3). Hasil analisis tersebut mengindikasikan bahwa sebagian besar pengelola sumber benih ternyata tidak bisa bertahan apabila terjadi penurunan permintaan bibit untuk proyek rehabilitasi lahan pemerintah yang dikombinasikan dengan kenaikan biaya produksi.

Tabel (Table) 3. Hasil analisis sensitivitas kelayakan finansial pengusahaan sumber benih (The result of sensitivity analysis on feasibility of seed sources business)

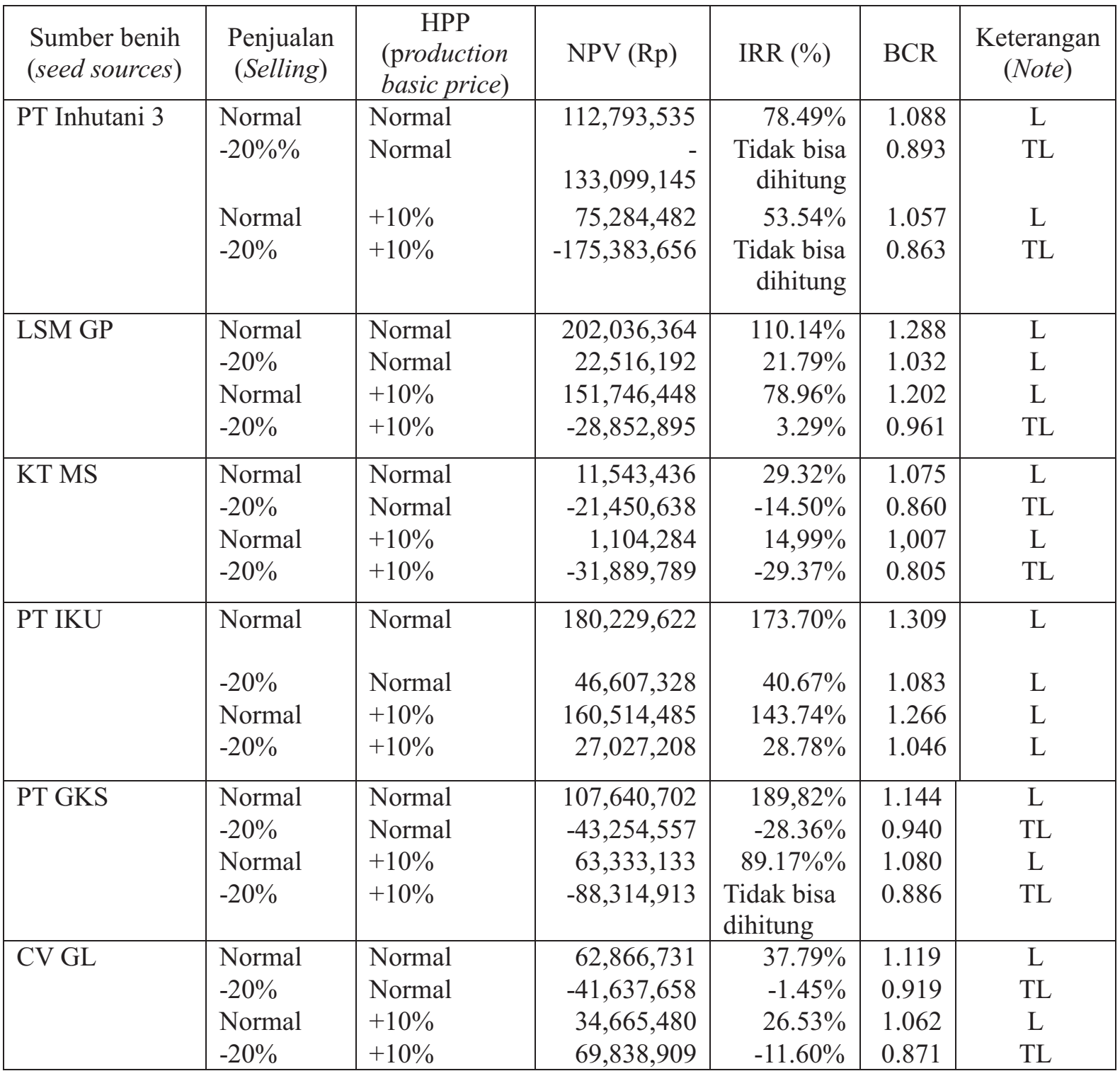

Keterangan : L : layak, TL : tidak layak

\section{Jalur tataniaga benih dan distribusi manfaat}

Dalam jalur tataniaga benih di Kalsel dan Kaltim, pengelola sumber benih bertindak sebagai produsen. Hasil produksi umumnya dalam bentuk bibit, kecuali di PT Inhutani 3 yang produknya berupa benih. Jadi produsen di sini sekaligus berperan sebagai penangkar bibit.
Terdapat beberapa tipe jalur tata niaga benih di Kalsel dan Kaltim, yaitu a) saluran langsung; b) saluran satu tingkat; c) saluran dua tingkat; d) saluran tiga tingkat. Jalur tataniaga pada masingmasing tipe saluran adalah sebagai berikut :

a) Pengelola SB Konsumen

b) Pengelola SB Pemborong Konsumen

c) Pengelola SB/Pengumpul Pemborong Konsumen 
d) Pengelola SB Pengumpul 1 Pengumpul 2 Pemborong konsumen

Pada saluran langsung, harga jual produsen sama dengan harga beli konsumen, sehingga $\mathrm{Fs}=1$. Sedangkan pada distribusi manfaat tipe saluran satu tingkat, ternyata pertimbangan adanya sertifikat dalam penentuan harga bibit menentukan besarnya marjin keuntungan pengelola sumber benih (Tabel 4). Sebgai contoh, pengelola sumber benih meranti di PT IKU yang memperhitungkan adanya sertifikat sumber benih dalam penentuan harga bibit mendapat marjin keuntungan yang lebih besar dari pemborong. Sedangkan rasio keuntungan dan biaya tidak berbeda jauh antara pengelola sumber benih dengan pemborong. Berbeda dengan sumber benih mahoni PT IKU yang harga jual bibitnya sama dengan harga jual bibit mahoni non sertifikat, sehingga marjin keuntungan yang diperoleh hanya berselisih sedikit dengan marjin keuntungan pemborong Namun rasio keuntungan dan biaya pemborong jauh lebih besar daripada pengelola sumber benih mahoni.

Tabel (Table) 4. Distribusi manfaat pada saluran pemasaran satu tingkat (The benefit distribution of one level trading path)

\begin{tabular}{|c|c|c|c|c|c|c|c|}
\hline \multirow[t]{3}{*}{ No } & \multirow[t]{3}{*}{ Lembaga (Institution) } & \multicolumn{3}{|c|}{ Meranti (Shorea sp.) } & \multicolumn{3}{|c|}{$\begin{array}{c}\text { Mahoni } \\
\text { (Swietenia macrophylla) }\end{array}$} \\
\hline & & \multicolumn{2}{|c|}{$\begin{array}{c}\text { Distribusi manfaat } \\
\text { (Benefit } \\
\text { distribution) } \\
\end{array}$} & \multirow{2}{*}{$\begin{array}{l}\text { Rasio } \\
\pi / \mathrm{C} \\
\text { (ratio } \\
\text { of } \\
\text { benefit } \\
\text { and } \\
\text { cost })\end{array}$} & \multicolumn{2}{|c|}{$\begin{array}{c}\text { Distribusi manfaat } \\
\text { (Benefit } \\
\text { distribution) }\end{array}$} & \multirow{2}{*}{$\begin{array}{l}\text { Rasio } \\
\pi / \mathrm{C} \\
(\text { ratio of } \\
\text { benefit } \\
\text { and } \\
\text { cost }))\end{array}$} \\
\hline & & $\begin{array}{c}\text { Harga } \\
\text { (price) } \\
(\mathrm{Rp} / \\
\text { batang) }\end{array}$ & $\begin{array}{l}\text { Share } \\
(\%)\end{array}$ & & $\begin{array}{c}\text { Harga } \\
\text { (price) } \\
(\mathrm{Rp} / \\
\text { batang) }\end{array}$ & $\begin{array}{l}\text { Share } \\
(\%)\end{array}$ & \\
\hline \multirow[t]{7}{*}{1.} & \multicolumn{7}{|l|}{ Pengelola SB/penangkar } \\
\hline & $\begin{array}{l}\text { Biaya-biaya }(\mathrm{C}) \text { : } \\
\text { - Biaya investasi }\end{array}$ & $\begin{array}{r}1102.67 \\
844.28\end{array}$ & $\begin{array}{l}55.13 \\
42.22\end{array}$ & & $\begin{array}{l}503.31 \\
868.94\end{array}$ & $\begin{array}{r}0.39 \\
26.71\end{array}$ & \\
\hline & - Biaya operasional & 179.6 & 8.98 & & 113.42 & 8.72 & \\
\hline & - Biaya pemasaran & 19.0 & 0.95 & & 24.27 & 1.87 & \\
\hline & - Harga jual & 1600.00 & 80.00 & & 800.00 & 61.54 & \\
\hline & Marjin keuntungan & 497.33 & 24.87 & & 296.69 & 22.82 & \\
\hline & Rasio $\pi / C$ & & & 0.451 & & & 0.59 \\
\hline \multirow[t]{7}{*}{2} & \multicolumn{7}{|l|}{ Pemborong } \\
\hline & \multirow{6}{*}{$\begin{array}{l}\text { Biaya-biaya : } \\
\text { - Biaya pemasaran } \\
\text { - Marjin pemasaran } \\
\text { - Marjin keuntungan } \\
\text { - Harga jual } \\
\text { Rasio } \pi / \mathrm{C} \\
\end{array}$} & 260.00 & \multicolumn{2}{|c|}{0.13} & 230 & 17.69 & \\
\hline & & 260.00 & 0,13 & & 230 & 17.69 & \\
\hline & & 400.00 & 20.00 & & 500.00 & 38.46 & \\
\hline & & 140.00 & 7.00 & & 290 & 22.31 & \\
\hline & & 2000.00 & 100.00 & & 1300 & 100 & \\
\hline & & \multicolumn{3}{|c|}{0.5} & \multicolumn{3}{|r|}{1.38} \\
\hline \multirow[t]{2}{*}{3} & \multicolumn{7}{|l|}{ Konsumen akhir } \\
\hline & Harga beli & 2000 & 100 & & 1300 & 100 & \\
\hline
\end{tabular}

Pada saluran dua tingkat yang menjadi contoh kasus adalah tataniaga bibit gaharu dari sumber benih PT GL di Kaltim. Distribusi manfaat dalam tipe saluran dua tingkat tersaji dalam Tabel 5 . 
Tabel (Table) 5. Distribusi manfaat dalam saluran pemasaran dua tingkat (The benefit distribution of two levels trading path)

\begin{tabular}{|c|c|c|c|c|}
\hline \multirow[t]{2}{*}{ No } & \multirow[t]{2}{*}{ Lembaga (Institution) } & \multicolumn{2}{|c|}{$\begin{array}{c}\text { Distribusi manfaat (benefit } \\
\text { distribution }\end{array}$} & \multirow{2}{*}{$\begin{array}{c}\text { Rasio } \\
\text { keuntungan dan } \\
\text { biaya (Ratio of } \\
\text { benefit and cost })\end{array}$} \\
\hline & & $\begin{array}{c}\text { Harga (price) } \\
\text { (Rp/batang) }\end{array}$ & Share $(\%)$ & \\
\hline \multirow[t]{8}{*}{1} & Pengelola SB/penangkar: & & & \\
\hline & Biaya-biaya (C): & 657.50 & 41.09 & \\
\hline & - Biaya investasi & 251.50 & 15.72 & \\
\hline & - Biaya operasional & 405.00 & 25.32 & \\
\hline & - Biaya pemasaran & 1.00 & 0.06 & \\
\hline & Harga jual & 900.00 & 56.25 & \\
\hline & Marjin keuntungan $(\pi)$ & 242.50 & 15.16 & \\
\hline & Rasio keuntungan dan biaya & & & 0.37 \\
\hline \multirow[t]{6}{*}{2} & Pengumpul: & & & \\
\hline & Biaya pemasaran & 11.00 & 0.69 & \\
\hline & Harga jual & 1000.00 & 62.50 & \\
\hline & Marjin pemasaran & 100.00 & 6.25 & \\
\hline & Marjin keuntungan $(\pi)$ & 89.00 & 5.56 & \\
\hline & Rasio keuntungan dan biaya & & & 8.09 \\
\hline \multirow[t]{6}{*}{3} & Pemborong: & & & \\
\hline & Biaya pemasaran & 220.00 & 13.75 & \\
\hline & Harga jual & 1600 & 100.00 & \\
\hline & Marjin pemasaran & 600.00 & 37.50 & \\
\hline & Marjin keuntungan $(\pi)$ & 380.00 & 23.75 & \\
\hline & Rasio keuntungan dan biaya & & & 1.72 \\
\hline 4 & $\begin{array}{l}\text { Konsumen akhir : } \\
\text { Harga beli }\end{array}$ & 1600 & 100.00 & \\
\hline
\end{tabular}

Pada tipe saluran dua tingkat yang mendapat rasio keuntungan dan biaya terbesar adalah pengumpul. Ini disebabkan pengumpul hanya mengeluarkan biaya pemasaran berupa biaya transportasi dan komunikasi. Pengumpul mengumpulkan bibit dari beberapa penangkar dan selanjutnya dijual kepada pemborong. Pemborong mendapatkan marjin keuntungan terbesar karena tingginya harga jual bibit, namun rasio keuntungan dan biaya pemborong lebih kecil dari pengumpul karena selain biaya transportasi, pemborong juga mengeluarkan biaya pemasaran untuk memenangkan tender pengadaan bibit, yang berupa biaya biaya komunikasi dan biaya negosiasi dengan pihak konsumen.

Saluran tiga tingkat terjadi karena adanya grup dalam tataniaga bibit tanaman hutan di Kaltim. Grup tersebut terdiri dari beberapa perusahaan yang berstatus PT dan CV.yang masing-masing dapat mengikuti tender pengadaan bibit. Anak grup pemenang tender bertindak sebagai pemborong, sementara anak grup lain menjadi pengumpul ke-2, sehingga stok bibit disubsidi silang antar perusahaan dalam grup. Distribusi manfaat dalam tipe saluran tiga tingkat tersaji dalam Tabel 6. 
Tabel (Table) 6. Distribusi manfaat pada saluran pemasaran tiga tingkat (The benefit distribution of three levels trading path)

\begin{tabular}{|c|c|c|c|c|}
\hline \multirow{2}{*}{ No } & \multirow{2}{*}{ Lembaga (Institution) } & \multicolumn{2}{|c|}{$\begin{array}{l}\text { Distribusi manfaat } \\
\text { (Benefit distribution) }\end{array}$} & \multirow{2}{*}{$\begin{array}{l}\text { Rasio keuntungan } \\
\text { dan biaya (Ratio of } \\
\text { benefit and cost) }\end{array}$} \\
\hline & & $\begin{array}{l}\text { Harga (price) } \\
\text { (Rp/batang) }\end{array}$ & $\begin{array}{c}\text { Share } \\
(\%)\end{array}$ & \\
\hline \multirow[t]{8}{*}{1} & \multirow{8}{*}{$\begin{array}{l}\text { Pengelola SB/penangkar: } \\
\text { Biaya-biaya }(\mathrm{C}) \text { : } \\
\text { - Biaya investasi } \\
\text { - Biaya operasional } \\
\text { - Biaya pemasaran } \\
\text { Harga jual } \\
\text { Marjin keuntungan }(\pi) \\
\text { Rasio keuntungan dan biaya }\end{array}$} & & & \\
\hline & & & 33.36 & \\
\hline & & 178.13 & 9.89 & \\
\hline & & 415 & 23.06 & \\
\hline & & 7.4 & 0.41 & \\
\hline & & 800.00 & 44.44 & \\
\hline & & 199.47 & 11.08 & \\
\hline & & \multicolumn{3}{|r|}{0.33} \\
\hline \multirow[t]{6}{*}{2} & \multicolumn{4}{|l|}{ Pengumpul 1} \\
\hline & \multirow{5}{*}{$\begin{array}{l}\text { Biaya pemasaran } \\
\text { Harga jual } \\
\text { Marjin pemasaran } \\
\text { Marjin keuntungan }(\pi) \\
\text { Rasio keuntungan dan biaya }\end{array}$} & 51.00 & 2.83 & \\
\hline & & 900.00 & 50.00 & \\
\hline & & 100.00 & 5.56 & \\
\hline & & 49.00 & 2.72 & \\
\hline & & \multicolumn{3}{|r|}{0.96} \\
\hline \multirow[t]{8}{*}{3} & \multicolumn{4}{|l|}{ Pengumpul 2: } \\
\hline & \multicolumn{4}{|l|}{ Biaya-biaya } \\
\hline & \multicolumn{4}{|l|}{ - Biaya transportasi } \\
\hline & \multicolumn{4}{|l|}{ - Biaya transaksi } \\
\hline & \multicolumn{4}{|l|}{ Harga jual } \\
\hline & \multirow{2}{*}{\multicolumn{4}{|c|}{$\begin{array}{l}\text { Marjin pemasaran } \\
\text { Marjin keuntungan }(\pi)\end{array}$}} \\
\hline & & & & \\
\hline & Rasio keuntungan dan biaya & \multicolumn{3}{|r|}{8.68} \\
\hline \multirow[t]{6}{*}{4} & \multirow{6}{*}{$\begin{array}{l}\text { Pemborong: } \\
\text { Biaya pemasaran } \\
\text { Harga jual } \\
\text { Marjin pemasaran } \\
\text { Marjin keuntungan }(\pi) \\
\text { Rasio keuntungan dan biaya }\end{array}$} & & & \\
\hline & & 260.00 & 14.44 & \\
\hline & & 1800 & 100.00 & \\
\hline & & 600.00 & 33.33 & \\
\hline & & 340.00 & 18.89 & \\
\hline & & \multicolumn{3}{|r|}{1.31} \\
\hline 5 & $\begin{array}{l}\text { Konsumen akhir : } \\
\text { Harga beli }\end{array}$ & 1800 & 100 & \\
\hline
\end{tabular}

Pada saluran tiga tingkat, yang mendapat rasio keuntungan dan biaya terbesar adalah pengumpul 2, yaitu anak grup yang bertindak sebagai pengumpul. Sementara marjin keuntungan terbesar diperoleh oleh pemborong. Pemborong mendapatkan marjin keuntungan terbesar karena tingginya harga jual bibit, namun rasio keuntungan dan biaya pemborong lebih kecil dari pengumpul 2 karena selain biaya transportasi, pemborong juga mengeluarkan biaya transaksi untuk memenangkan tender pengadaan bibit.

Pada saluran pemasaran satu, dua, dan tiga tingkat dimungkinkan terjadinya pencampuran antara bibit dari sumber benih bersertifikat dengan non sertifikat, karena adanya pengumpul dan pemborong yang mengumpulkan bibit dari berbagai penangkar, sehingga mutu bibit tidak terjamin.

Dari hasil analisis distribusi manfaat diketahui bahwa makin panjang saluran, makin kecil Farmer's Share (FS) yang diperoleh pengelola sumber benih. Demikian pula dengan persentase marjin keuntungan, makin panjang saluran, makin kecil marjin keuntungan yang diperoleh pengelola sumber benih. Mubyarto (1982) menyatakan bahwa efisiensi saluran pemasaran atau tataiaga terfokus pada efisiensi 
kerja suatu sistem pemasaran yang digunakan petani, yang menentukan bagian harga yang diterima petani (Farmer's Share) dalam menerima bagian harga dari pembayaran harga terakhir. Apabila petani salah dalam memilih rantai tataniaga dalam memasarkan produknya, maka petani akan mengalami kerugian karena bagian yang diterima petani lebih rendah dari yang diharapkan. Menurut Soekartawi (1989), dalam hal ini konsumen juga akan dirugikan karena saluran pemasaran yang tidak efisien.

Pada saluran satu tingkat untuk jenis meranti, marjin keuntungan pengelola sumber benih lebih besar atau seimbang dengan pemborong. Ini disebabkan pengelola sumber benih mempunyai posisi tawar dan informasi pasar yang lebih baik daripada pengelola sumber benih di saluran dua dan tiga tingkat, sehingga tidak terjadi buyer driven (harga ditentukan pembeli). Berbeda dengan distribusi manfaat saluran satu tingkat untuk bibit mahoni, serta saluran dua dan tiga tingkat, di mana pengelola sumber benih menyesuaikan dengan harga pasar yang menyamakan antara bibit dari SB bersertiifikat dengan non sertifikat. Ini terjadi karena ketidakseimbangan informasi (assymetric information) yang dimiliki pengelola sumber benih dengan pengumpul atau pemborong. Ketidakseimbangan informasi ini meliputi jenis, harga, kuantitas, dan kualitas bibit yang dikehendaki pasar, serta waktu tender pengadaan bibit. Faktor waktu memegang peranan penting karena bibit memiliki masa kadaluarsa. Bibit yang terlalu tua biasanya tidak laku terjual sehingga penangkar bibit merugi. Aspek infomasi pasar sangat penting agar dapat mendekati kondisi pasar sempurna (Kotler, 2002), yang dapat menghasilkan kepuasan bagi semua pelaku tataniaga, baik pengelola sumber benih, penangkar, pedagang pengumpul, dan pemborong.

\section{KESIMPULAN DAN SARAN}

\section{A. Kesimpulan}

1. Kelembagaan sertifikasi sumber benih tanaman hutan di Kalimantan Timur dan Kalimantan Selatan sudah efisien dari sudut pandang pengelola sumber benih bersertifikat.

2. Pengusahaan sumber benih bersertifikat ternyata layak dari segi finansial, dan biaya transaksi sertifikasi yang dikeluarkan tidak signifikan dibanding dengan keuntungan yang diperoleh.

3. Pengusahaan sumber benih bersertifikat sensitif terhadap penurunan pendapatan sebesar $20 \%$, atau kenaikan biaya produksi sebesar 10\%, atau kombinasi keduanya.

4. Distribusi manfaat antar pelaku tataniaga ternyata belum seimbang. Farmer's Share (FS) terbesar dan distribusi marjin keuntungan paling seimbang diperoleh pada saluran langsung dan saluran tingkat satu, dengan syarat harga bibit mempertimbangkan adanya sertifikasi sumber benih.

5. Distribusi informasi yang meliputi infomasi kebijakan, teknologi perbenihan, dan infomasi pasar ternyata belum bisa menjangkau seluruh pelaku dalam kegiatan sertifikasi sumber benih tanaman hutan.

\section{B. SARAN}

1. Direktorat Jenderal Rehabilitasi Lahan dan Perhutanan Sosial agar segera mengeluarkan pedoman teknis sertifikasi sumber benih sebagai penjabaran Permenhut P.1/2009, termasuk ketentuan mengenai besaran pungutan jasa penerbitan sertifikasi yang diperkenankan.

2. Pengelolaan sumber benih bersertifikat ternyata layak dan menguntungkan secara finansial, sehingga disarankan Dinas Kehutanan dapat lebih aktif melakukan pembinaan dan pengawasan terhadap sumber benih, sebab berprospek sebagai sumber pendapatan daerah (PAD). PAD bisa didapat dari pungutan jasa penerbitan sertifikat maupun retribusi, asalkan besarnya proporsional dan tidak memberatkan pengusaha benih.

3. Kepada para pengusaha perbenihan, disarankan agar membentuk forum komunikasi perbenihan di tingkat propinsi sebagai wahana tukar menukar informasi teknologi, ketersediaan benih dan atau bibit, serta informasi pasar.

4. Kepada kalangan akademisi dan peneliti, disarankan agar melakukan penelitian permodelan untuk mengetahui besarnya pungutan jasa penerbitan sertifikasi yang layak bagi pengusahaan sumber benih.

\section{DAFTAR PUSTAKA}

Bank Indonesia. 2009. Suku Bunga Rata-rata Kredit Bank Berdasar Sektor Ekonomi. 
Http://www.bi.go.id/NR/rdonlyres/5EF57 BBE-E879-4263-958F-5FDA87201AE5/ 17840/BISPIJuln2009.pdf. Diakses tanggal 8 November 2009.

Falah, F., T. Atmoko, dan Suhardi. 2008. Laporan Hasil Penelitian Kelembagaan Sertifikasi Sumber Benih Tanaman Hutan di Wilayah Kalimantan T.A. 2008. Balai Penelitian Teknologi Perbenihan Tanaman Hutan Samboja. Tidak dipublikasikan.

Kohl, R. and J. Uhl. 2002. Market Structure, Conduct and Performances of Some Selected Large Countries. Diunduh dari http://www.etd.aau.edu.et. Pada tanggal 16 Februari 2009.

Kotler, P. 2002. Manajemen Pemasaran Jilid 1. Edisi Milenium. Prenhallindo. Jakarta.

Mubyarto. 1989. Pengantar Ekonomi Pertanian. LP3ES. Jakarta.
North, D.C. 1991. Institutions, Institutional Change and Economic Performance. Political Economy of Institutions and Decisions. Cambridge University Press. Cambridge.

Peraturan Menteri Kehutanan No P.01/MenhutII/2009 tentang Penyelenggaraan Perbenihan Tanaman Hutan.

Peraturan Menteri Kehutanan No P.72/MenhutII/2009 tentang Perubahan atas Peraturan Menteri Kehutanan No P.01/MenhutII/2009 tentang Penyelenggaraan Perbenihan Tanaman Hutan.

Soekartawi. 1989. Prinsip-prinsip Dasar Ekonomi Pertanian, Teori dan Aplikasinya. Rajawali Press. Jakarta

Yustika, A.E. 2006. Ekonomi Kelembagaan : Definisi, Teori, dan Strategi. Bayumedia. Malang. 